REVIEW

\title{
Adolescent and young adult tobacco prevention and cessation: current status and future directions
}

\author{
C L Backinger, P Fagan, E Matthews, R Grana
}

Tobacco Control 2003;12(Suppl IV):iv46-iv53

See end of article for authors' affiliations

Correspondence to:

Cathy Backinger, 6130

Executive Blvd, EPN 4036

Rockville, MD 20852,

USA;

backingc@mail.nih.gov
Objective: To summarise the evidence on adolescent and young adult prevention and cessation, and provide future directions for research.

Data sources: Data were collected from published literature. Searches for adolescent prevention were conducted using PubMed, Psyclnfo, and ERIC; and for cessation, PubMed, and two major reviews that span January 1978 to May 2002. PubMed, Psychlnfo, and SCCl were searched for young adults from January 1990 to May 2002.

Study selection: Data included smoking prevention studies published from January 1990 to May 2002 and conducted in the USA; all identified smoking cessation studies for adolescents. Young adult data were limited to initiation and cessation studies.

Data extraction: Extraction of data was by consensus of the authors.

Data synthesis: Results of the review are qualitative in nature using a consensus approach of the authors. Conclusions: School based curricula alone have been generally ineffective in the long term in preventing adolescents from initiating tobacco use but are effective when combined with other approaches such as media and smoke-free policies. Prevention research should consider multiple approaches and the social conditions that influence the development of youth problem behaviours including tobacco use. Because youth smoking cessation has been understudied to date, scientifically rigorous adolescent smoking cessation studies need to be conducted with attention to high risk smokers and less than daily smokers. Tobacco prevention and cessation for young adults needs focused attention. Prevention and cessation programmes need to address other tobacco products in addition to cigarettes.
$\mathrm{T}$ obacco use among youth in the USA has declined following considerable increases in the early 1990s. From 1991 to 1997, current smoking prevalence among high school students increased significantly from $27.5 \%$ to $36.4 \%{ }^{1}$ In 2001, 28.5\% of high school students reported current smoking compared to $36.4 \%$ in $1997 .{ }^{1}$ The Centers for Disease Control and Prevention (CDC) report that factors that may have contributed to this decline include the increase in the price of cigarettes and increased exposure to smoking prevention media campaigns. Data from the Monitoring the Future study indicate a similar downward trend among eighth, 10th, and 12th graders. ${ }^{2}$ Although these recent declines are encouraging, much progress is needed to achieve the Healthy People 2010 objectives to reduce tobacco use in the USA. ${ }^{3}$

Reducing tobacco use in the USA goes beyond just focusing on adolescents. Nearly $90 \%$ of adult smokers indicate that they first started smoking before the age of 18 years ${ }^{4}$ and it has been assumed that if one could get past the adolescent years without smoking, then one would not begin smoking as an adult. However, the cumulative risk of smoking initiation does not begin to plateau until age $22 .{ }^{5}{ }^{6}$ During the early 1990s, smoking among young adults began to fluctuate after nearly 16 years of sustained decline. Recent data indicate that first use rates for those aged 18-25 years increased from 1993 to 1995 and first daily use fluctuated for the same years. ${ }^{7}$ In 1999, data from the National Health Interview Survey indicate that smoking rates among young adults were higher than in the 25-44 year old age group. This rate of $27.9 \%$ represents a notable change in trends because current smoking has historically been significantly lower among young adults than other adults. ${ }^{8}$ Although data from various national surveys indicate slightly different trends, data from the National Household Survey on Drug Abuse indicate an increase in cigarette use among young adults from $34.6 \%$ in 1994 to $41.6 \%$ in 1998. Similar to trends among adolescents, these data indicate a slight decline from $39.7 \%$ in 1999 to $38.3 \%$ in 2000 . $^{9}$ During young adulthood, non-smokers may be initiating smoking, smokers may be transitioning from experimentation to regular smoking, and they may be transitioning from non-dependent smokers to dependent smokers.

Identifying effective prevention and cessation programmes for adolescents and young adults is extremely critical. Teasing out the weight of the evidence for effective intervention components is one of the challenges that researchers and practitioners face. This endeavour, however, provides valuable information on components to consider for effective tobacco control programmes at the national, state, and local levels. This paper provides an overview of recent, published literature in the area of adolescent and young adult cigarette smoking prevention and cessation and offers future directions for research. Although youth and young adults use other forms of tobacco, this paper will focus primarily on cigarette smoking because the preponderance of research has been conducted in this area.

\section{METHODS}

Because a previous review of the adolescent smoking prevention literature is presented in the 1994 Surgeon's

\footnotetext{
Abbreviations: ADHD, attention deficit hyperactivity disorder; CARDIA, Coronary Artery Risk Development In young Adults; CDC, Centers for Disease Control and Prevention; ERIC, Educational Research Information Center; Project TNT, Project Towards No Tobacco Use; SSCI, Social Sciences Citation Index; YTCC, Youth Tobacco Cessation Collaborative
} 
General report Preventing tobacco use among young people, this paper provides an overview of major findings from US smoking prevention intervention studies published from January 1990 to May 2002. These studies were identified through a search using PubMed, PsycInfo and ERIC (Educational Research Information Center). Search terms included "smoking", "prevention", "intervention studies", "intervention trials", and "adolescence". The overview of adolescent tobacco cessation programmes presents the major findings from existing reviews by Sussman and the Youth Tobacco Cessation Collaborative (YTCC) and include reviews of the published literature from 1978 to 2001. Because a dearth of youth tobacco cessation research has been published compared with youth prevention studies, all cessation studies were included, regardless of year of publication or geographic study location. A search of PubMed using the search terms "adolescent", "tobacco use cessation", "smoking cessation", and "quit" found two additional studies not included in either the Sussman or YTCC review. For young adults, a search of PubMed, PsychInfo, and Social Sciences Citation Index (SCCI) was conducted from January 1990 to May 2002. Search terms included "young adults", "smoking", and "cessation".

This overview is not intended to provide an exhaustive literature review, but aims to highlight recent published intervention studies as a basis for discussing future research directions for adolescent and young adult tobacco prevention and cessation. The overview is organised in the following manner: adolescent smoking prevention including school based programmes, community based programmes, and policy initiatives, adolescent smoking cessation, young adult smoking prevention, and young adult smoking cessation.

\section{OVERVIEW OF LITERATURE \\ Adolescent smoking prevention}

Recent dialogue on youth tobacco use prevention has suggested that macro-level approaches can be effective in reducing the prevalence of tobacco use among adolescents. ${ }^{10}$ Counter-marketing campaigns, increased tobacco taxation, and stronger tobacco control policy have all shown to be successful strategies for preventing and reducing youth tobacco use. ${ }^{10}$ More focused "micro-level" interventions, such as school based social influences programmes, and community based and local media programming have provided insight into potentially effective and ineffective methods of reducing tobacco use initiation.

\section{School based prevention}

In the early 1980s smoking prevention programmes were focused primarily in school based settings. ${ }^{4}$ Nearly all studies reviewed from 1990 to 2002 had a school based component, if not a total focus on such programming. A number of studies have found school based prevention programmes to have short term effects (that is, immediately following intervention) in delaying smoking initiation and enhancing attitudes against smoking. ${ }^{11-15}$ There is very little evidence, however, to suggest long term prevention effectiveness. ${ }^{11-13}{ }^{16}$ A metaanalysis of school based prevention programmes, controlling for unit of analysis as well as experimental assignment, showed limited efficacy (an average effect size of 0.10 standard deviation units), indicating a need to explore alternative settings for tobacco use prevention. ${ }^{17}$

Much of early tobacco use prevention research was centred on the evaluation of school based social influences programming. Although there have been variations in the implementation of this approach, the basic underlying principle has been that training youth during early adolescence to resist social pressures to use tobacco can help to prevent initiation. ${ }^{15}$ When adapted to meet the needs of youth living in a tobacco producing region (considered "high risk" for their proximity to tobacco production and their community's relative social acceptance of tobacco), the social influences approach in the school setting was found to have only modest effects in reducing tobacco use at one and two years postintervention, though greater (yet still modest) effects were shown among those individuals who were personally involved in tobacco production. No significant difference in lifetime smoking was reported, however, between experimental and control conditions. ${ }^{14}$

Sussman and colleagues posited that it might be possible to discern the differential effects of the three most common components of social influences, thereby revealing the most effective components. ${ }^{15}$ Although additional evidence is needed to determine their long term effects, five approaches were studied: informational social influences, normative social influences, physical consequences of smoking, a combination of the three approaches, and a control condition of a "standard" curriculum. The combined social influences approach was found to be most effective when compared with the control condition for initial and weekly cigarette use. Informational social influences, physical consequences, and combined conditions were superior to both normative social influences and the control condition. Sussman and colleagues concluded that the heterogeneous nature of the social influences school based curriculum, Project Towards No Tobacco Use (Project TNT), contributed to its overall success addressing multiple determinants of smoking initiation and persistence. ${ }^{15} 18$

Building on the successful Life Skills Training programme, ${ }^{19} 0^{20}$ Botvin and colleagues examined the social resistance and competence enhancement approach for drug abuse prevention, including tobacco prevention, among urban minority youth which included blacks and Hispanics, as well as girls. In general, this programme teaches resistance skills in the broader context of promoting personal and social competence such as communication skills and coping with anxiety, and has been found to be effective..$^{21-23}$

Elder and colleagues went beyond examining social influences and considered other factors associated with smoking among youth. A school based study was conducted in the early 1990s to evaluate the effectiveness of a three year tobacco use prevention programme for youth using telephone boosters delivered by college undergraduate students. ${ }^{16}$ The classroom curriculum included refusal skills training, contingency management, and anti-tobacco activism activities delivered in grades 7-9 in 11 intervention schools, and was followed by mailing and telephone boosters. Results indicate that at both the school level and individual level, those in the intervention group were significantly more likely to report past month smoking than students in the control group. Elder and his colleagues initiated a secondary study in an effort to discern the relative effects of continued, lapsed, and delayed implementation of this programme. ${ }^{13}$ In contrast to the initial study which found no positive effect of the intervention, participants in both continued intervention and delayed intervention groups reported significantly less smoking than continued control and lapsed intervention participants.

In light of the strength of study design and implementation of the Hutchinson Smoking Prevention Project reported in $2000^{24} 25$ and findings from previous studies, ${ }^{11}{ }^{13-16}$ there is sufficient reason to conclude that social influences programming alone is not effective in the long term prevention of youth tobacco use initiation.

\section{Community based programmes}

Although numerous tobacco use prevention programmes have been developed and delivered over the past 30 years, few 
studies have systematically examined the effects of such interventions in community settings. There is some evidence to support multi-modal programming that combines school and community based components. Biglan and colleagues developed and implemented such a randomised controlled trial of comprehensive community programming for tobacco use prevention. ${ }^{26}$ Targeting key social influences contributing to youth tobacco use, this intervention combined media advocacy, family communications, product sales deterrents, and anti-tobacco activities to reduce youth tobacco use prevalence. Results indicate that a comprehensive community programme targeting multiple determinants of tobacco use in youth can enhance the effects of a school based programme alone. The effects of the intervention were significant at one year into the intervention and one year post-implementation, and were reported to have prevented an increase in prevalence in the community condition.

Mass media, in combination with school based programming, has also shown significant impacts on smoking prevalence. ${ }^{27-30}$ Such interventions have proved effective in targeting higher risk youth-that is, those who reported smoking at baseline, or who had immediate social contacts, such as family and friends who were smokers. ${ }^{27} 28$ Furthermore, there is evidence that effects of media and school based combined interventions may be durable. ${ }^{29}$ Students exposed to a mass media intervention in combination with a school based tobacco use prevention programme were found to be at reduced risk for weekly smoking when compared with students exposed only to the school based programming. Carefully addressing specific youth audiences through formative research and development of relevant media messages has been suggested to be crucial to the success of media based interventions. ${ }^{27-30}$ Combining mass media with school based programming addresses multiple social influences of youth tobacco use and represents an approach that reaches both youth who attend and do not attend school. ${ }^{27}{ }^{28}$ Results of the Minnesota-Wisconsin Adolescent Tobacco Use Research Project, a long term, broad based programme, which includes school based programming in combination with mass media and community grants, indicated that despite increased exposure to antismoking messages and information, weekly smoking rates were not significantly affected, indicating a need for more intensive programming. ${ }^{31}{ }^{32}$ Similarly, results from a field study of three media campaigns using two modalities (television and radio) combined with a peer involvement component showed only modest effects on expected consequences of smoking and friend approval of smoking. ${ }^{33}$ Neither modality proved more effective than the other, and effects on smoking could not be detected. Perry and colleagues evaluated tobacco specific classes and classes augmented with anti-smoking advertising, health screenings, and community based activities, and reported $11 \%$ and $22 \%$ weekly smoking prevalence in 10th grade students for intervention and control groups, respectively. ${ }^{34}$

\section{Policy initiatives}

Studies of statewide prevention programming have shown that legislative initiatives alone may not be sufficient to produce significant impacts on tobacco use prevalence. ${ }^{31}{ }^{32}$ Tobacco control policies seek to reduce tobacco use prevalence through smoking bans and enactment and enforcement of laws restricting youth access to tobacco products. Studies show that adolescents who live in smoke-free homes are less likely to smoke than adolescents in homes that do not restrict smoking. ${ }^{35}$ In addition, adolescents are less likely to smoke if they work in smoke-free workplaces than in workplaces without smoke-free policies. ${ }^{35}$ Though federal initiatives such as the Synar amendment, which requires that states receiving federal funding for substance abuse and treatment adopt and enforce tobacco age-of-sale laws, have been put into place, little has been done to study the effectiveness of such measures on prevalence. Studies on youth access show that young people continue to obtain cigarettes both from non-commercial sources, such as friends and family members, and from commercial sources, such as convenience stores, even though cigarette sales are prohibited to individuals under the age of 18 years. ${ }^{10}$ Jason and colleagues, however, found that strict enforcement of merchants reduces youth tobacco prevalence. ${ }^{3637}$ Forster and colleagues examined the effects of a community mobilisation programme in a randomised controlled trial and found that communities in the experimental condition who passed comprehensive youth access ordinances demonstrated a less pronounced increase in daily smoking during the intervention period than control communities. ${ }^{38}$ Data on the effect of cost show that youth are more responsive to cigarette price increases than adults, with a $10 \%$ increase in the price of cigarettes estimated to reduce youth smoking by approximately $5 \%$, as compared to $1-2 \%$ among adults. ${ }^{10}$ Estimates by economists report that youth are up to three times more sensitive to price than adults, highlighting that raising cigarette prices will reduce smoking prevalence among youth, as well as reduce the amount that youth smoke. ${ }^{39-41}$

\section{Adolescent smoking cessation}

The vast majority of tobacco cessation efforts have primarily focused on adults with an emphasis on regular daily smokers. In the 1980s there was a dearth of evidence on youth cessation, but since then the body of research has grown. Sussman recently updated a previous review of adolescent smoking cessation studies. ${ }^{42}$ The previous review, published in 1999, examined 17 studies reporting a wide range of outcomes. ${ }^{43}$ Because of methodological limitations such as use of single group design in 10 of the studies, and small sample sizes, it is difficult to draw any definitive conclusions regarding cessation results from these studies. ${ }^{44}$ In the 2002 review, Sussman analysed 66 tobacco cessation intervention studies from both published and unpublished literature conducted predominantly in the USA and studies conducted in nine other countries. These studies date from 1975 to January 2001 and reported a mean quit rate of $12 \%$ at $3-12$ months follow up. The mean quit rate for the control groups was $7 \%$. Length of follow up varied from two weeks to 64 months. Fourteen studies did not examine cessation past the end of the programme, while the other 52 studies reported the following time lengths for follow up: 10 studies at 1-2 months, 16 studies at 3-5 months, 11 studies at 6-7 months, 9 studies at 12 months, 4 studies at 1-2 years, and 2 studies at $\geqslant 3$ years. This review found that interventions using motivation enhancement or contingency based reinforcement had higher quit rates, $19 \%$ and $17 \%$ respectively, than other intervention theories. When examining effect by type of programme, classroom based programmes had the highest quit rate at $19 \%$ and computer based and school based clinics showed promise with $13 \%$ and $12 \%$ quit rates, respectively. These quit rates were derived from averaging all quit rates from each study category. Sussman concluded that even when taking into account missing data and variations in measurements, overall data suggest that quit rates double with tobacco cessation interventions.

As a follow up to this review, members of the Youth Tobacco Cessation Collaborative (YTCC) and invited scientists reviewed youth tobacco cessation studies for the strength of the evidence. ${ }^{44 a}$ The YTCC was formed in 1998 by representatives from major US and Canadian research organisations to address the acknowledged gap in adolescent tobacco 
cessation programmes and research projects. In response to the demand for tobacco cessation programmes by young smokers, schools, and communities, YTCC sought to determine the scientific evidence for supporting particular programmes in order to provide sound recommendations. Review elements included intervention adherence, implementation compliance, study design, sample size at initiation, duration of follow up post-intervention, cessation outcome, validation of smoking mechanism, retention, intent to treat analysis, and adherence fidelity. The YTCC review group focused on those studies with the strongest methodological design and subsequently included 20 studies for development of conclusions. ${ }^{11}{ }^{45-64}$ For example, those studies that used a randomised controlled design with 250 or more participants in each arm of the study and a duration of follow up postintervention of six months or more, were rated of higher quality than those using a single group design with less than 30 participants and no time duration of follow up postintervention. The inclusion criteria differed from Sussman in that the YTCC group weighted the quality of the studies based on the elements listed above, while Sussman treated all studies equally. In addition, YTCC reviewed only those studies that had a cessation end point and did not include those that only reported a reduction in smoking. The review found that tobacco cessation intervention programmes employing a cognitive behavioural approach to be promising in terms of helping adolescents quit smoking.

Two published studies addressing adolescent smoking cessation were not included in either the Sussman or YTCC reviews. Adelman and colleagues reported a positive effect of a school based smoking cessation programme compared with an information pamphlet among high school students. ${ }^{65}$ At 20 weeks post-curriculum, $41 \%(\mathrm{n}=14)$ and $31 \%(\mathrm{n}=12)$ were smoke-free, as confirmed by salivary cotinine tests. The other study evaluated laser acupuncture in a randomised placebo controlled trial of 330 adolescent smokers and found no difference between treatment and control. ${ }^{66}$ Four weeks after treatment, $21.9 \%$ of the treatment group and $21.4 \%$ of the control group reported not smoking.

Few studies have been conducted with the use of pharmacological aids for adolescent smoking cessation. Two published studies evaluating nicotine patch for smoking cessation in youth have found the patch to be ineffective. ${ }^{58} 59$ A recent study at the University of Minnesota showed no significant difference in 30 day point prevalence rates between active and placebo nicotine patches for smoking abstinence at end of treatment. ${ }^{67}$ Twenty per cent of adolescent smokers, aged 13-19 years and smoking at least 10 cigarettes per day for six months, reported abstinence compared with $18 \%$ in the placebo patch group. The researchers, however, reported higher abstinence rates than in previous nicotine patch studies with youth.

\section{Young adult smoking prevention}

Research and programmes for young adults have largely been overlooked because of the traditional focus on youth prevention and adult cessation. Evidence from tobacco industry document archives, that were made available to the public by tobacco litigation, revealed that young adults were recognised by the industry as a new market long before a critical mass of public health researchers began to seriously discuss the problem of tobacco use among young adults. Document evidence suggests that in the mid 1980s, the RJ Reynolds company developed specific strategies to engender a young adult market. ${ }^{68}$ A 1983 plan for "field marketing" indicated that person-to-person interaction at parties, concerts, and nightclubs became a popular strategy to reach the young adult market. It is possible that these marketing techniques contributed to recent reported increases in smoking among young adults.

Several populations of young adults are particularly at risk for initiation. Results from the Coronary Artery Risk Development In young Adults (CARDIA) study of young adults indicate that from 1986 to 1996 smoking initiation rates were highest among young African American adults. ${ }^{69}$ Initiation rates were consistently higher among those with high school education or less, except among white women, where initiation rates were highest for women with some college education. The CARDIA study also found differences in initiation rates by birth cohorts. Initiation rates were generally higher in younger cohorts than older, with the exception of black women. Initiation rates were consistently higher in black men than women across birth cohorts. Data from the Harvard College alcohol study indicate that between 1993 and 1997, smoking prevalence increased by $28 \%$ among college students. ${ }^{70}$ Data from these studies support the notion that young adults over the age of 18 years are at risk for smoking initiation and that education, sex, and race/ethnicity are sociodemographic factors to consider when examining initiation rates among young adults. Although it is not clear if initiation rates increase among blue collar and service workers, youth that transition to the labour force may be at increased risk for smoking. Studies indicate that adolescents who work long hours are at increased risk for smoking than those who work fewer hours. ${ }^{70-74}$ About one third of youth report that they first started smoking at work. ${ }^{75}$ In addition, data from adult studies indicate that service and blue collar workers are at greater risk for smoking than white collar workers. $^{76}{ }^{77}$ A recent unpublished study found that young adult blue collar and service workers are at greater risk for smoking than white collar workers, and the unemployed are at greater risk for smoking than the employed. (Lawrence et al, unpublished data).

Beyond sociodemographic factors, few studies have examined other factors associated with smoking initiation rates among young adults. In 1993, Daly and colleagues investigated factors associated with smoking initiation among women in Minnesota and found that smoking by a spouse or significant other and perceived acceptability of smoking by friends were the most significant predictors of smoking among young adult women. ${ }^{78}$

\section{Young adult smoking cessation}

Studies on cessation among adults neglect to report the differential effects of interventions on young adult cessation. However, data from the North Karelia study indicate that the quit rate among young adults is similar to other adult populations $(2.3 \%){ }^{79}$ In this study, cessation rates were higher among females than males, married compared to divorced, white collar than blue collar, and employed compared to unemployed. No differences among cessation rates were observed by educational level. Another study reported no differences for smoking cessation between a computer, stages of change based cessation programme, and a health education programme for college student smokers at seven month follow up. ${ }^{80}$

Although there is a dearth of intervention data on young adults, there are several factors to consider when developing young adult tobacco cessation programmes. Evidence suggests that age of onset, dependence, psychological disorders, and college education are important factors to consider for young adult cessation. ${ }^{81-83}$ Furthermore, daily smoking, ${ }^{84}$ race/ ethnicity, sex, and education level are associated with cessation rates among young adults. ${ }^{68}$ Pirie and colleagues, in a follow up study of adolescents two years out of high school, found sex differences in smoking and quitting behaviour, with young women more likely to be current 
smokers. ${ }^{85}$ Although men in general tended to report more withdrawal symptoms, women were more likely to report weight gain and desire to eat more than men. These studies suggest that additional research is needed to examine nicotine dependence among young adult smokers and develop interventions targeting young adults to help them quit smoking.

\section{FUTURE DIRECTIONS}

\section{Adolescent smoking prevention}

Review of the published literature suggests that tobacco prevention using school based curricula alone have generally been ineffective. The CDC has identified only two school based programmes as effective curricula in reducing tobacco use among young people: Life Skills Training and Project Towards No Tobacco Use (Project TNT). ${ }^{86}$ Both Life Skills Training and Project TNT go beyond a one-dimensional approach to tobacco prevention and address multiple determinants of tobacco use. Life Skills Training is designed for students in grades 6 through 9 (approximately 11-15 years of age) and example objectives include saying "no" to tobacco, alcohol, and other drugs; developing a positive self image; and making independent decisions without being influenced by peers, media, and others. ${ }^{19}{ }^{20}$ Project TNT is designed for youth ages 10-15 years and example objectives include reducing initiation or regular use of tobacco products; educating students about tobacco addiction and disease, the health consequences of using tobacco, and the prevalence of tobacco use among peers; building self esteem; teaching social messages that influence tobacco use; and understanding ways media portray social images that influence tobacco use..$^{15} 18$

Studies examining community based and policy initiatives to prevent tobacco use suggest that utilising approaches such as mass media and smoking bans, in addition to school based programmes, can be effective in preventing tobacco use among adolescents. Recommendations from the 2001 National Cancer Institute monograph, Changing adolescent smoking prevalence: where it is and why, suggest that sustained, comprehensive programmes work and that these efforts need further testing to examine their long term effects on initiation. ${ }^{10}$ These comprehensive tobacco programmes address the range of influences on youth tobacco use, such as tobacco-free policies, active parent and community involvement, school based programmes, cessation services, and media to counter tobacco advertising. Research is also needed that address youth empowerment and youth involvement as tools that contribute to initiating social change.

While gains have been made with regard to new knowledge in the areas of adolescent tobacco use prevention, continued work needs to focus on several areas of inquiry. Despite the promise held by the multi-modal tobacco prevention approaches described in this paper, it is clear that full trajectory of smoking does not occur in a vacuum. Multiple social, psychological, biologic, and environmental influences contribute to youth smoking, and therefore need to be addressed. ${ }^{4}$ For example, a study by Whalen and colleagues found that those with high level attention deficit hyperactivity disorder (ADHD) were 10 times more likely to smoke that those adolescents with low level ADHD. ${ }^{87}$ Another study reported that early experimenters of tobacco and smokers were more likely to experience problem behaviours such as early pregnancy, dropping out of high school, stealing, and other illegal behaviours. ${ }^{88}$ Orlando and colleagues also found that emotional distress reported in grade 10 was associated with smoking in grade 12 for both boys and girls. ${ }^{89}$ Patten and colleagues found that cigarette smoking is associated with sleep problems in youth aged $12-18$ years. ${ }^{90}$
Further study of prevention interventions using multiple approaches, and addressing tobacco use within the social context of youth, is warranted..$^{1011} 1524263132$ Additional research that examines the small group of multi-problem youth that account for a large and costly proportion of youth problem behaviours is needed. In 2000, the National Cancer Institute, National Institutes of Health (NIH) Office of AIDS Research, NIH Office of Behavioral and Social Sciences Research, National Institute on Drug Abuse, National Institute on Alcohol and Alcohol Abuse, National Institute of Mental Health, and the Robert Wood Johnson Foundation funded a special project on multiple problem youth at the Center for Advanced Study in the Behavioral Sciences, in Stanford, California. This project brought together a multidisciplinary team of scientists to examine the current weight of the evidence on the prevention of multiple problems in youth and recommend ways in which to improve the prevention strategies of behaviours such as tobacco use, alcohol and other drug use, and risky sexual behaviour. These scientists found adolescents who are engaged in antisocial behaviour, such as physical fighting and stealing, are more likely to smoke, drink alcohol, use illicit drugs, and experience academic failure. While multiple problem behaviour youth account for only a small percentage of the entire youth population, they commit up to $60 \%$ of general crime committed by youth and almost $80 \%$ of violent offences committed by youth. In addition, data from the National Longitudinal Study of Adolescent Health ${ }^{91}$ show that of the $11 \%$ of adolescents reporting smoking, $85 \%$ of them also engaged in at least one other problem behaviour (unpublished data).

Interventions aimed at preventing multiple problem behaviours in youth could help prevent tobacco use. Research has demonstrated that parenting programmes that increase parent skills in reinforcing appropriate behaviour, establishing parental rules, and monitoring children's activities have been shown to reduce youth antisocial behaviour. In addition, effective school instruction improves academic performance. Consequently, initiatives are needed to address the common social conditions that influence the development of these youth problem behaviours if we are to make gains in preventing smoking in youth.

\section{Young adult smoking prevention}

In 2000, one third of young adults were enrolled in college with at least half of them participating in the labour force. ${ }^{92}$ While the majority of the young adults who were not enrolled in school were in the workforce, about $10 \%$ of $16-24$ year olds were unemployed. The unemployment rate for African Americans was $20.3 \%$, which is about twice the rate of other race/ethnic groups. Employment and unemployment rates indicate that it may be important to explore both worksite and community settings to reach young adults at risk for smoking. Because unemployed persons in all age groups have largely been ignored in tobacco control, little is known about addressing smoking in this population. Epidemiological studies on patterns of use and risk factors are needed to identify effective components for tobacco control programmes for the unemployed. This is particularly important to examine in young adults because it is not clear if there is an association between the high unemployment rates in young adulthood and high prevalence rates among African American male adults. Data from adolescent studies indicate that approximately one-third of youth reported that they first tried cigarettes at work. ${ }^{75}$ Studies are needed to explore factors that influence smoking initiation, heavy smoking, and quit behaviours among workers at risk for smoking and determine the association between smoking among young adults and social factors in the work environment. 


\section{Adolescent and young adult nicotine dependence and tobacco cessation}

Studies to date suggest that additional research is needed to examine nicotine dependence among youth and young adult smokers and develop effective interventions to help them quit smoking. Researchers at Brown University and their collaborators reviewed the empirical literature to determine nicotine dependence and withdrawal in adolescent cigarette smokers. Compared with adult smokers, adolescents were less likely to smoke daily or with regularity, and adolescent daily smokers smoked fewer cigarettes. Despite this smoking pattern, $20-68 \%$ of adolescent smokers were considered dependent on nicotine and at least $66 \%$ of smokers reported some form of withdrawal upon cutting down or quitting smoking. ${ }^{93}$ In the first controlled prospective study to examine the effects of nicotine deprivation in youth, Killen and colleagues. found that youth experience both subjective changes such anxiety and restlessness, as well as objective changes such as decrease in heart rate, when deprived of nicotine. ${ }^{94}$ DiFranza and colleagues found that the pattern of nicotine dependence among youth does not parallel the smoking uptake continuum specified by Flay and associates ${ }^{4}$ - that is, progression from experimental tobacco use to occasional use, then to daily use that increases in frequency, resulting in dependence that can take several months to years. Their study found that $63 \%$ of seventh grade students, aged 12-13 years, who had smoked at least once a month, exhibited one or more symptoms of nicotine dependence. ${ }^{95}$ Among these students, $22 \%$ reported symptoms of nicotine dependence within four weeks of initiating monthly smoking. Based on this study, DiFranza and colleagues developed the "autonomy theory" whereby loss of autonomy, when either the physical or psychological effects of nicotine present a barrier to quitting, signals onset of dependence. ${ }^{96}$

Interventions with adolescents and young adults should take into consideration various consumptive patterns when designing cessation programmes; they should determine if there is a need for distinct interventions for less than daily smokers and smokers who are not yet dependent on nicotine and more intensive interventions for heavier smokers and those with psychiatric disorders. Nicotine dependence and withdrawal studies in youth have important implications for tobacco cessation research. One possible reason why recent cessation studies have not been successful in helping youth quit smoking is that youth who are less than daily smokers are excluded from cessation programmes. In addition, because there are sex differences in cessation rates, studies may consider tailoring interventions for males and females. ${ }^{94}{ }^{95}$ Young adults who initiate late smoking and college students may experience greater success at quitting than earlier initiators. In addition, studies should consider sociodemographic factors when developing cessation programmes for young adults and specifically tailor interventions for those at high risk, including blue collar workers and the unemployed.

\section{Multiple forms of tobacco use}

Any prevention and cessation programme for adolescents or young adults need to consider multiple tobacco use. Although the predominant form of tobacco use by youth and young adults is cigarettes, both populations use bidis, kreteks, cigars, and smokeless tobacco. Smokeless tobacco includes both chewing tobacco and snuff; bidis are flavoured cigarettes primarily from India; and kreteks are cigarettes that contain both cloves and tobacco. Thirty five per cent of high school students report using any form of tobacco within the past 30 days. ${ }^{97}$ In 2000 , US high school students reported current use of the following tobacco products in these percentages: cigarettes $28 \%$, smokeless tobacco $6.6 \%$, cigars

\section{What this paper adds}

Numerous studies have been conducted addressing tobacco use prevention among adolescents, and have found, in general, that school based social influences curricula have not been effective in the long term. Comprehensive programmes combining school based programmes, however, with community based and policy initiatives have been found to be effective. Future research should employ multiple approaches, as well as address common social conditions that influence the development of youth problem behaviours including tobacco use. Because of the dearth of studies conducted on youth cessation, as well as many with methodological limitations, results have not been encouraging and continued research is needed. Prevention and cessation studies also need to be conducted with young adults, including those in the work force and those enrolled in college.

$14.8 \%$, pipes $3.3 \%$, bidis $4.1 \%$, and kreteks $4.2 \% .{ }^{97}$ Researchers have also found that multiple forms of tobacco use are prevalent among college students. ${ }^{98}$ In one study of college students, $51.3 \%$ had used more than one tobacco product in the past year. Of all students in the sample, $8.5 \%$ were current users of cigars, $3.7 \%$ of smokeless tobacco, and $1.2 \%$ used pipes. ${ }^{99}$ Few studies address the multiple tobacco use behaviours and these should be addressed when conducting research and implementing prevention and cessation programmes.

\section{SUMMARY AND CONCLUSIONS}

In general, school based curricula alone have been ineffective in the long term in preventing adolescents from initiating tobacco use. Evidence exists to support multi-modal programming for preventing tobacco use among adolescents, including combining school and community based programmes, combining mass media and school based programmes, and combining smoking bans with school based programmes. Examining the long term impact of tobacco use prevention programmes on youth smoking is critical, and teasing out the most effective components of micro- and macro-level programmes will provide practitioners with valuable information on how to develop more successful adolescent tobacco prevention programmes. In addition, prevention research needs to focus on multiple approaches and the social conditions that influence the development of youth problem behaviours, including tobacco use.

An insufficient number of scientifically rigorous adolescent smoking cessation studies have been conducted. Although inadequate evidence exists concerning effective programmes overall, the cognitive behavioural approach for adolescent smoking cessation appears promising. Most studies to date have been conducted either in classrooms or schools, and it is clear from the published literature that more innovative studies using a variety of methods and settings are needed if we are to be successful in helping youth quit tobacco. Future research needs to study a variety of approaches of sound methodological design and address high risk smokers and less than daily smokers.

Tobacco prevention and cessation for young adults is an understudied area because of the traditional focus on adolescent tobacco prevention and adult cessation. With tobacco industry marketing to young adults and increased smoking rates among this population, there is a need to examine factors associated with initiation rates and develop and test interventions for preventing initiation in the young adult population. Cessation interventions conducted in a 
variety of settings, including blue collar and service work settings, and not just the secondary school setting, may help reach the diverse audience of young adults at risk for smoking and address the multiple levels of influence that these settings may have on their smoking behaviour.

Although cigarette smoking is the predominant form of tobacco use in the USA, use of other tobacco products needs to be considered in prevention and cessation programmes for adolescents and young adults. Youth and young adults may not smoke cigarettes exclusively and addressing tobacco use, overall, is warranted.

\section{Authors' affiliations}

C L Backinger, P Fagan, E Matthews, Tobacco Control Research Branch, National Cancer Institute, Bethesda, Maryland, USA

R Grana, MasiMax Resources, Inc, Rockville, Maryland, USA

\section{REFERENCES}

1 Centers for Disease Control and Prevention. Trends in cigarette smoking among high school students - United States, 1991-2001. MMWR Morb Mortal Wkly Rep 2002;51:409-12.

2 Johnston LD, O'Malley PM. Bachman JG. Monitoring the future; national results on adolescent drug use: overview of key findings, 2001. Bethesda, Maryland: National Institute on Drug Use, 2002. (NIH Publication No. 025105, 2002.)

3 US Department of Health and Human Services. Healthy People 2010 (conference ed, 2 vols). Washington DC: US Department of Health and Human Services, 2000.

4 US Department of Health and Human Services. Preventing tobacco use among young people. A report of the Surgeon General, 1994. Atlanta, Georgia: Public Health Service, Centers for Disease Control and Prevention, Office on Smoking and Health, 1994. (US Government Printing Office Publication No S/N 017-001-00491-0.)

5 Centers for Disease Control and Prevention. Cumulative age of initiation of cigarette smoking*. - United States, 1991. http://www.cdc.gov/tobacco/ research data/youth/init.htm

6 DeWit DJ, Offord DR, Wong M. Patterns of onset and cessation of drug use over the early part of the life course. Health Educ Behav 1997;24:746-58.

7 U.S. Department of Health and Human Services. Cigarette smoking among adults - incidence of initiation of cigarette smoking - United States, 19651996. Centers for Disease Control and Prevention. MMWR Morb Mortal Wkly Rep 1998;47:837-48.

8 US Department of Health and Human Services. Cigarette smoking among adults - United States, 1998. Centers for Disease Control and Prevention. MMWR Morb Mortal Wkly Rep 2000:49:881-4.

9 Substance Use and Mental Health Services Administration. Tobacco use in America: findings from the 1999 National Household Survey on Drug Abuse. http://www.drugabusestatistics.samhsa.gov

10 National Cancer Institute. Changing ddolescent smoking prevalence Smoking and Tobacco Control Monograph No. 14. Bethesda, Maryland: US Department of Health and Human Services, National Institutes of Health, National Cancer Institute, 2001. (NIH Publication No. 02-5086.)

11 Ary DV, Biglan A, Glasgow R, et al. The efficacy of social-influence prevention programs versus "standard care": are new initiatives needed? J Behav Med 1990;13:281-96.

12 Cella DF, Tulsky DS, Sarafian B, et al. Culturally relevant smoking prevention for minority youth. J School Health 1992:62:377-80.

13 Eckhardt L, Woodruff SI, Elder JP. Related effectiveness of continued, lapsed, and delayed smoking prevention intervention in senior high school students. Am J Health Promot 1997; 11:418-21.

14 Noland MP, Kryscio RJ, Riggs RS, et al. The effectiveness of a tobacco prevention program with adolescents living in a tobacco-producing region. Am J Public Health 1998;88:1862-5.

15 Sussman S, Dent CW, Stacy AW, et al. Project towards no tobacco use: 1 year behavior outcomes. Am J Public Health 1993:83:1245-50.

16 Elder JP, Wildey M, de Moor C, et al. The long-term prevention of tobacco use among junior high school students: classroom and telephone interventions. Am J Public Health 1993;83:1239-44.

17 Rooney BL, Murray DM. A meta-analysis of smoking prevention programs after adjustment for errors in the unit of analysis. Health Educ $Q$ 1996:23:48-64.

18 Dent CW, Sussman S, Stacey AW, et al. Two-year behavior outcomes of Project Towards No Tobacco Use. J Clin Consulting Psych 1995;63:676-77.

19 Botvin GJ, Eng A. The efficacy of a multicomponent approach to the prevention of cigarette smoking. Prev Med 1982;11:199-211.

20 Botvin GJ. Eng A, Williams CL. Preventing the onset of cigarette smoking through life skills training. Prev Med 1980;9:135-43.

21 Botvin GJ, Dusenbury L, Baker E, et al. Smoking prevention among urban minority youth: assessing effects on outcome and mediating variables. Health Psychol 1992;11:290-9.

22 Botvin GJ, Griffen KW, Diaz T, et al. Drug abuse prevention among minority adolesecents: posttest and one-year follow-up of a school-based preventive intervention. Prev Sci $2001 ; 2: 1-13$.
23 Botvin GJ, Griffen KW, Diaz T, et al. Smoking initiation and escalation in early adolescent girls: one-year follow-up of a school-based prevention intervention for minority youth. J Am Med Womens Assoc 1999;54:139-43, 152.

24 Peterson AV, Kealey KA, Mann SL, et al. Hutchinson smoking prevention project: long-term randomized trial in school-based tobacco use prevention results on smoking. J Ntl Cancer Inst 2000;92:1979-91.

25 Mann SL, Peterson AV, Marek PM, et al. The Hutchinson smoking prevention project trial: design and baseline characteristics. Prev Med 2000;30:485-95.

26 Biglan A, Ary DV, Smolkowski K, et al. A randomised controlled trial of a community intervention to prevent adolescent tobacco use. Tobacco Control 2000;9:24-32

27 Flynn BS, Worden JK, Secker-Walker RH, et al. Long-term responses of higher and lower risk youths to smoking prevention interventions. Prev Med 1997;26:389-94.

28 Worden JK, Flynn BS, Solomon $\sqcup$, et al. Using mass media to preven cigarette smoking among adolescent girls. Health Educ Q 1996;23:453-68.

29 Flynn BS, Worden JK, Secker-Walker RH, et al. Mass media and school interventions for cigarette smoking prevention: effects 2 years after completion. Am J Public Health 1994;84: $1148-50$.

30 Flynn BS, Worden JK, Secker-Walker RH, et al. Prevention of cigarette smoking through mass media intervention and school programs. Am J Public Health 1992:82:827-34.

31 Murray DM, Perry CL, Griffin G, et al. Results from a statewide approach to adolescent tobacco use prevention. Prev Med 1992;21:449-72.

32 Murray DM, Prokhorov AV, Harty KC. Effects of a statewide antismoking campaign on mass media messages and smoking beliefs. Prev Med 1994:23:54-60.

33 Bauman KE, LaPrelle J, Brown JD, et al. The influence of three mass media campaigns on variables related to adolescent cigarette smoking: results of a field experiment. Am J Public Health 1991;81:597-604.

34 Perry CL, Kelder SH, Murray DM, et al. Community-wide smoking prevention: long-term outcomes of the Minnesota heart health program and the class of 1989 study. Am J Public Health 1992;82:1210-6.

35 Farkas AD, Gilpin EA, White MM, et al. Association between household and workplace smoking restrictions and adolescent smoking. JAMA 2000;284:717-22

36 Jason L, Berk M, Schnopp-Wyatt $D$, et al. Effects of enforcement of youth access laws on smoking prevalence. Am J Comm Psych 1999;27:143-60

37 Jason L, Katz R, Vavra J, et al. Long term follow-up on youth access to tabacco law's impact on smoking prevalence. J Human Behav Soc Environ 1999:2:1-13.

38 Forster JL, Murray DM, Wolfson M, et al. The effects of community policies to reduce youth access to tobacco. Am J Public Health 1998;88:1193-8.

39 Chaloupka FJ, Grossman M. Tobacco control policies and youth smoking. National Bureau of Economic Research Working Paper No. W5740, 1996.

40 Evans WN, Farrelly MC. The compensating behavior of smokers: taxes, tar, and nicotine. RAND J Econ 1998;29:578-95

41 Lewit E, Hyland A, Kerrebrock N, et al. Price, public policy and smoking in youth people. Tobacco Control 1997:6(suppl 2):17-24.

42 Sussman S. Effects of sixty six adolescent tobacco use cessation trials and seventeen prospective studies of self-initiated quitting. Tobacco Induced Diseases 2002;1:35-81.

43 Sussman S, Lichtman K, Ritt A, et al. Effects of thirty-four adolescent tobacco use cessation and prevention trials on regular users of tobacco products. Substance Use Misuse 1999;34:1469-503.

44 Backinger CL, Leischow SJ. Advancing the science of adolescent tobacco use cessation. Am J Health Behav 2001 ;25:183-90.

44a McDonald P, Colwell B, Backinger CL, et al. Better practices for youth tobacco cessation: evidence of a review panel. Am J Health Behavior 2003;27(Suppl 2):S144-57.

45 Dino GA, Horn KA, Zedosky $L$, et al. A positive response to teen smoking: Why N-O-T? National Association of Secondary School Principals $1998 \cdot 82 \cdot 46-58$.

46 Patten CA, Ames SC, Ebbert JO, et al. Tobacco use outcomes of adolescents treated clinically for nicotine dependence. Arch Pediatr Adolesc Med 2001;155:831-7.

47 Glasgow RE, Strychker LA, Eakin EG, et al. Concern about weight gain associated with quitting smoking: Prevalence and association with outcome in a sample of young female smokers. J Consult Clin Psychol 1999;67:1009-11.

48 Digiusto $E$. Pros and cons of cessation interventions for adolescent smokers at school. In: Richmond R, ed. Interventions for smokers: an international perspective. Baltimore, Maryland: Williams \& Wilkins, 1994:107-36.

49 Sussman S, Dent CW, Burton D, et al. Developing a school based tobacco use prevention and cessation programs. Thousand Oaks, California: Sage Publications, 1995

50 Eakin E, Severson H, Glasgow RE. Development and evaluation of a smokeless tobacco cessation program: a pilot study. Ntl Cancer Inst Monographs 1989;8:95-100.

51 Dino GA, Horn KA, Goldcamp J, et al. State-wide demonstration of Not On Tobacco: a gender-sensitive teen smoking cessation program. J Sch Nurs 2001;17:90-7

52 Horn K, Dino G, Gao X, et al. Feasibility evaluation of Not On Tobacco: the ALA's new stop smoking program for adolescents. Health Education 1999:99:192-206.

53 Dino G, Horn K, Goldcamp J, et al. A 2-year efficacy study of not on tobacco in Florida: an overview of program successes in changing teen smoking behavior. Prev Med 2001;33:600-5.

54 Bauman KE, Ennett ST, Foshee VA, et al. Influence of a family-directed program on adolescent cigarette and alcohol cessation. Prev Sci 2000;1:227-37. 
55 Colby SM, Monti PM, Barnett NP, et al. Brief motivational interviewing in a hospital setting for adolescent smoking: a preliminary study. J Consul Clin Psychol 1998;66:574-8

56 Sussman S, Dent CW, Lichtman KL. Project EX: outcomes of a teen smoking cessation program. Addict Behav 2001;26:425-38.

57 Baskerville B, Hotte A, Dunkley G. Evaluation of a high school Quit and Win smoking-cessation program. Community Health Research Unit, University of Ottawa, 1993.

58 Hurt RD, Croghan GA, Beede SC, et al. Nicotine patch therapy in 101 adolescent smokers: efficacy, withdrawal symptom relief, and carbon monoxide, and plasma cotinine levels. Arch Pediatr Adolesc Med 2000;154:31-7.

59 Smith TA, House RF, Croghan IT, et al. Nicotine patch therapy in adolescent smokers. Pediatrics 1996:98:659-67.

60 Aveyard P, Cheng KK, Almond J, et al. Cluster randomised controlled trial of expert system based on the transtheoretical ("stages of change ${ }^{\prime \prime}$ ) model for smoking prevention and cessation in schools. BMJ 1999;319:948-53.

61 Coleman-Wallace D, Lee JW, Montgomery S, et al. Evaluation of developmentally appropriate programs for adolescent tobacco cessation. J Sch Health 1999;69:314-19.

62 Pallonen UE, Velicher WF, Prochaska JO, et al. Computer-based smoking cessation interventions in adolescents: description, feasibility, and six month follow-up findings. Subst Use Misuse 1998;33:1-31.

63 Greenberg JS, Deputat Z. Smoking intervention: comparing three methods in a high school setting. J Sch Health 1978;48:498-502.

64 Burton D, Chakravorty B, Weeks K, et al. Outcome of the TNT tobaccocessation randomized trial with high-school students. (unpublished).

65 Adelman WP, Duggan AD, Hauptman $P$, et al. Effectiveness of a high school smoking cessation program. Pediatrics 2001;107:E50.

66 Yiming C, Changxin Z, Ung WS, et al. Laser acupuncture for adolescent smokers - a randomized double-blind controlled trial. Am J Chin Med 2000;28(3-4):443-9.

67 Hanson K, Allen S, Jensen S, et al. Treatment of adolescent smokers with the nicotine patch. Nicotine and Tobacco Research 2003;5:515-26.

68 Sepe E, Ling PM, Glantz SA. Smooth moves: bar and nightclub tobacco promotions that target young adults. Am J Public Health 2002:92:414-9.

69 Wagenknecht LE, Craven TE, Preisser JS, et al. Ten-year trends in cigarette smoking among young adults, 1986-1996: the CARDIA study. AEP 1998;8:301-7.

70 Wechsler H, Rigotti NA, Gledhill-Hoyt J, et al. Increased levels of cigarette use among college students: a cause for national concern, JAMA 1998;280:1673-8.

71 Greenberger A, Steinberg L, Vaux A. Adolescents who work: health and behavioral consequences of job stress. Dev Psychol 1981;17:691-703.

72 Resnick MD, Bearman PS, Blum RW, et al. Protecting adolescents from harm. Findings from the National longitudinal study on adolescent health. JAMA 1997;278:823-32.

73 Stanton W, Oei T, Silva P. Socio-demographic characteristics of adolescent smokers. Int J Add́liction 1994;29:913-25.

74 Valois RF, Dunham ACA, Jackson KL, et al. Association between employment and substance abuse behavior among public high school adolescents. $J$ Adolesc Health 1999;25:256-63.

75 Borland R, Chapman S, Owen N, et al. Effects of workplace smoking bans on cigarette consumption. Am J Public Health 1990;80:178-80.

76 US Department of Health and Human Services. The health consequences of smoking: cancer and chronic lung disease in the workplace. A report of the Surgeon General, 1985. Rockville, Maryland: Public Health Service, Office on Smoking and Health, 1985. (DHHS Publication No (CDC) 85-50207.)

77 Shopland DR, Hartman AM, Gibson JT, et al. Cigarette smoking among U.S. adults by state and region: Estimates from the current population I Natl Cancer Inst 1996;88:1748-58.
78 Daly KA, Lund EM, Harty KC, et al. Factors associated with late smoking initiation in Minnesota women. Am J Public Health 1993;83:1333-5.

79 Paavola M, Vartianen E, Puska P. Smoking cessation between teenage years and adulthood. Health Educ Res 2001;16:49-57.

80 O'Neill HK, Gillespie MA, Slobin K. Stages of change and smoking cessation: a computer-administered intervention program for young adults. Am J Health Promot 2000;15:93-6.

81 Breslau N, Kilbey MM, Andreski P. Nicotine dependence, major depression, and anxiety in young adults. Arch Gen Psychiatry 1991;48:1069-74.

82 Breslau N, Kilbey MM, Andreski P. Vulnerability to psychopathology in nicotine-dependent smoker: an epidemiologic study of young adults. Am J Psychiatry 1993;150:941-6.

83 Breslau N, Peterson EL. Smoking cessation in young adults: age at initiation of cigarette smoking and other suspected influences. Am J Public Health 1996;86:214-20.

84 Husten CG, McCarty MC, Giovino G, et al. Intermittent smokers: a descriptive analysis of persons who have never smoked daily. Am J Public Health 1998;88:86-9.

85 Pirie PL, Murray DM, Luepker RV. Gender differences in cigarette smoking and quitting in a cohort of young adults. Am J Public Health 1991;81:324-7.

86 Centers for Disease Control and Prevention. Criteria for entry into the programs that work process. http://www.cdc.gov/nccdphp/dash/rtc/ criteria.htm.

87 Whalen CK, Jamner LD, Henker B, et al. Smoking and moods in adolescents with depressive and aggressive dispositions: evidence from surveys and electronic diaries. Health Psychol 2001;20:99-111.

88 Ellickson PL, Tucher JS, Klein DJ. High-risk behaviors associated with early smoking: results from a 5-year follow-up. J Adolesc Health 2001;28:465-73.

89 Orlando M, Ellickson PL, Jinnett K. The temporal relationship between emotional distress and cigarettes during adolescence and young adulthood. J Consult Clin Psychol 2001;69:959-70.

90 Patten CA, Choi WS, Gillin JC, et al. Depressive symptoms and cigarette smoking predict development and persistence of sleep problems in US adolescents. Pediatrics 2000;106:E23.

91 The National Longitudinal Study of Adolescent Health. http:// www.cpc.unc.edu/projects/addhealth.

92 Unites States Department of Labor. Table 2. Labor force status of persons 16 to 24 years old by school enrollment, education al attainment, sex, race, and Hispanic origin, October 2001. http://stats.bls.gov/news.release/ hsgec.t02.htm

93 Colby SM, Tiffany ST, Shiffman S, et al. Are adolescent smokers dependent on nicotine? A review of the evidence. Drug and Alcohol Dependence 2000;59(suppl 1):S83-95.

94 Killen JD, Ammerman S, Rojas N, et al. Do adolescent smokers experience withdrawal effects when deprived of nicotine? Exp Clin Psychopharmacol 2001;9:176-82.

95 Difranza JR, Rigotti N, McNeill AD, et al. Initial symptoms of nicotine dependence in adolescents. Tobacco Control 2000;9:313-19.

96 Difranza JR, Savageau JA, Fletcher K, et al. Measuring the loss of autonomy over nicotine use in adolescents: The DANDY Development and assessment of nicotine dependence in youths (DANDY) study. Arch Pediatr Adolesc Med 2002; 156:397-403.

97 Centers for Disease Control and Prevention. Smoking attributable mortality and years of potential life lost - United States, 1995-1999. MMWR Morb Mortal Wkly Rep 2002;51:300-3.

98 Jamner MS. Cigar smoking among college students: Prevalence and correlates. Prev Med 1999;29:187-94

99 Rigotti NA, Lee JE, Wechsler H. US college students' use of tobacco products. Results of a national Survey. JAMA 2000;284:699-705. 